elephants in Malaysia (Rice, 1990; L. Ratnam and S. Daim, pers comm.).

The usefulness of translocation as a management tool in such cases thus appears to be in serious doubt and further investigation is needed. Accordingly, it has been proposed by the present writer that the Wildlife Institute of India should carry out the following research:

(i) Monitoring movements of elephants after translocation in contiguous forest areas with the help of radio-telemetry.

(ii) Verifying if the matriarch (or some other animal of a different age-group) from a herd, translocated but kept tethered at the release point, could bring back the herd to that area as a response to the infrasonic distress calls emitted by the captured animal. If successful, this could be a useful tool to guide straying elephant herds, an increasingly frequent phenomenon in India, back to their normal home range (Panwar and Johnsingh, 1989).

(iii) All reported cases of return of translocated elephants concern animals removed from their original home range. It needs to be ascertained whether the same behaviour pattern would occur when straying herds are translocated back to their original home range.]

\section{K. Lahiri-Choudhury 45 Suhasini Ganguly Sarani Calcutta 700 025, India}

\section{References}

Appayya, M.K. Undated. Operation Elephant Translocation. Mimeo. Karnakata Forest Department, India. 6pp.

Hofmeyr, J.M. 1979. Diary of the Deduru Oya Elephant Capture, Sri Lanka 1979. Unpublished mimeo reprint. $35 \mathrm{pp}$.

Khan, M.B.M.K. 1987. The status, distribution and conservation of elephant in Peninsular Malaysia. In Action Plan for Asian Elephant Conservation (draft) (Compiler, C. Santiapillai). World Wide Fund for Nature, Switzerland.

Lahiri-Choudhury, D.K. 1988. Aggression in young elephants. Hornbill, 1988 (2), 28-39.

Lahiri-Choudhury, D.K. 1990. Translocating elephants. The India Magazine, 10, 12-21.

Lahiri-Choudhury, D.K. 1991. Translocation of Wild Elephants. Technical Report No. 1. Asian Elephant Conservation Centre of IUCN/SSC. Asian Elephant Specialist Group, Bangalore.

Panwar, H.S. and Johnsingh, A.J.T. 1989. Elephant Conservation in India: Problems and Prospects. Wildlife Institute of India, Dehra Dun, Uttar Pradesh, India. Mimeo. 26 pp.

Rice, C. 1990. Don't forget to pack the trunk. Wildlife Conservation, 93 (4), 58-67.

\title{
Monkey business in Gibraltar
}

The population of Barbary macaques Macaca sylvanus in Gibraltar, described as a 'unique colony of a Vulnerable species' (IUCN, 1988), is still at risk despite attempts to improve its prospects.

There are now approximately 105 macaques in Gibraltar, living in two main areas, Middle Hill and Queen's Gate. Since 1972 only the latter colony has been accessible to visitors and this has borne the brunt of tourism. Since 1985, when the land-frontier with Spain was fully opened, visitor numbers have increased almost fourfold. In the peak summer months about 1000 people a day visit the 31 monkeys at Queen's Gate (Fa, 1991).

There have been concerns about the impact of tourism on the macaques for many years. Particularly worrying is the fact that tourists offer the animals sweets and other unsuitable foods, which causes obesity and dental decay and has been linked to a lowered birth-rate and reduced lifespan (Fa, 1984, 1988). Both the military authorities, traditionally in charge of the monkeys, and biologists recognized the need to limit feeding of unsuitable foods and to improve visitor-monkey contact conditions (Fa, 1984; Carver, 1987). 
A proposal for a self-financing monkey park in 11 ha of the Upper Rock was developed (Fa and Pankhurst, 1982) and this was endorsed by the Primate Society of Great Britain and the International Conference on the Conservation of the Barbary Macaque in 1982. Despite discussion, the park proposals have not been implemented (Fa, 1987).

The responsibility for management of the Queen's Gate site was given to the Gibraltar Tourism Agency (GTAL), who, in July 1990 contracted MEDAMBIOS (an environmental consultancy) to run the site as a tourist attraction. Under this arrangement the situation improved, with MEDAMBIOS providing wardens who maintained site cleanliness, attempted to control traffic flow and tried to prevent tourists offering unsuitable food to the animals. The Gibraltar Regiment retained its traditional responsibility for the feeding and welfare of all macaques in Gibraltar and full responsibility for the Middle Hill group. Despite the improvements, the divided nature of management responsibilities impeded real progress towards improving the status of the monkeys. Tourist literature generally promotes the image of cute, appealing 'apes', stressing their historical association with British presence on The Rock. There is little awareness or appreciation of the monkeys as wild animals. As well as the feeding problems, the close contact with tourists poses risks of disease transmission and perpetrates a 'circustype' atmosphere, which militates against respect for the animals' natural integrity.

In June-September 1991 I carried out research at Queen's Gate to reassess the level, nature and extent of human-macaque interactions. Observations were complemented by interviews with 200 visitors. Among the findings was the fact that macaques spent 41.9 per cent of their day 'inactive' and 13.2 per cent interacting with humans or their vehicles. The monkeys have clearly adapted their diurnal activity to visitor patterns; similar adaptations have been reported for other wild primates capitalizing on human food handouts (Else, 1991; Zhao, 1991). Humans initiated interactions three times as often as monkeys did and were especially attracted to groups containing newborn infants, usually offering food to enable a closer approach. Such close contact poses risk of disease to young vulnerable animals. In 1987 a pneumonia epidemic killed all the infants of that year. Human contact was believed to have been the source of infection.

There were signs that campaigns to reduce the offering of cariegenic/calorie-rich food had had some effect. In 1991 only 15.2 per cent of the food offered was unsuitable compared with 40 per cent in the 1980 s. With 61 per cent of all human-initiated interactions involving food, the volume rather than the nature of the food reaching the animals is now the main problem.

Few visitors showed an appreciation of the 1 macaques as wild animals. Only 40 per cent of visitors at Queen's Gate had come specifically to see the monkeys and only 40 per cent of these listed 'natural history interest' among their reasons. For most visitors the 'apes' were just one of the sights that one had to see in Gibraltar.

An alarming 82 per cent of interviewees thought that the monkeys were 'about the right weight'. This absence of any perception of a weight problem must be addressed if visitor behaviour and monkey health is to be improved. While 68.5 per cent of visitors thought that feeding had some negative effects on the monkeys' health and behaviour, only 53 per cent thought that if visitor access were more controlled it would be better for the monkeys.

The GTAL originally brought in Dr Fa of MEDAMBIOS to implement the Monkey Park proposals. The contract to MEDAMBIOS to develop the Apes' Den site was also described by GTAL as 'Phase One' of the full implementation of the park's development. However, recent events suggest that GTAL currently has little interest in realizing the full park development. On 16 April 1992 GTAL broke its 5-year management contract with MEDAMBIOS, nominally because the altered status of the Apes' Den within the Upper Rock Nature Reserve made a contract with a private company not feasible. Yet GTAL is now running the Apes' Den site itself, with no formal consultation with experienced and interested bod- 
ies such as MEDAMBIOS, the Gibraltar Ornithological and Historical Society, the Gibraltar Heritage Trust, or the Institute of Mediterranean Ecology. While a vet has been contracted to provide emergency care, emphasis is on cure rather than prevention, with no clear plans for regular monitoring of the health of the animals. Part-time cleaners have replaced the full-time wardens, so that for substantial parts of the day there is no one to advise visitors or control their behaviour. The GTAL does not appear to be planning any scientific management policy for the monkey population at Queen's Gate or Middle Hill.

Ironically, on 1 April a large section of the Upper Rock, including the Apes' Den area, was declared an Official Nature Reserve. So far, it seems to be very much a reserve on paper only: it has no wardens and no means of enforcing or controlling activities relating to the Gibraltar Nature Protection Ordinance (1991). The Barbary macaque is listed on this as a Schedule 1 'Wild' animal, so it is disquieting that a commercially orientated body such as the Tourist Office should be given such a large measure of control over the monkey population on Gibraltar.

\section{Helen O'Leary, c/o The Old Rectory, Petworth, West Sussex GU28 ODB, UK}

\section{Acknowledgments}

I should like to thank the Universities Federation for Animal Welfare, The Royal Anthropological Society and the Primate Society of Great Britain for their financial assistance for the fieldwork, and M. $\mathrm{H}$. Bland and Co. for free travel on the cable car.

\section{References}

Carver, J.F. 1987. Routine AVRO report to the Gibraltar regiment. November 1987.

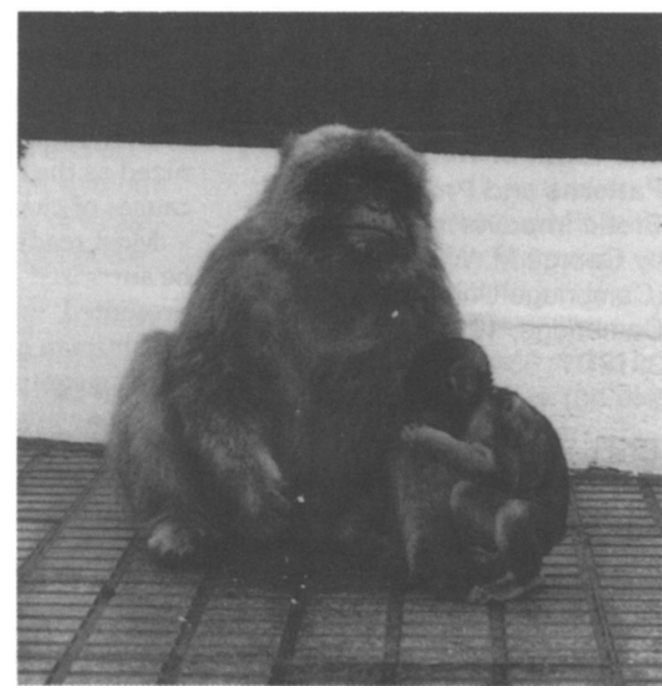

Many adult Barbary macaques are noticeably overweight. Close human-macaque contact increases risk of disease transmission to vulnerable infants (H. O'Leary).

Else, J.G. 1991. Nonhuman primates as pests. In Primate responses to Environmental Change (ed. $\mathrm{H}$. O. Box), pp. 155-167. Chapman and Hall, London.

Fa, J. E. 1984. The Barbary Macaque - A Case Study in Conservation. Plenum, New York.

Fa, J. E. 1987. A monkey park for Gibraltar? Oryx, 21, 242-245.

Fa, J. E. 1988. Supplemental food as an extranormal stimulus in Barbary macaques at Gibraltar - its impact on activity budgets. In Ecology and Behaviour of Food-enhanced Primate Groups (eds J. E. Fa and C. H. Southwick), pp. 53-56. Alan Liss, New York.

Fa, J. E. 1992. Visitor directed aggression amongst the Gibraltar macaques - biting the hand that feeds. Zoo Biology, 11, 43-52.

Fa, J. E. and Pankhurst, I. 1982. Gibraltar Monkey Park Development Proposals. Mimeo report to the Gibraltar Government.

IUCN, 1988. 1988 Red List of Threatened Animals. IUCN, Gland, Switzerland and Cambridge, UK.

Zhao, Qui-Kun. 1991 (in press). Dramatic consequences of food handouts to $\mathrm{M}$. thibetana at $\mathrm{Mt}$ Eimei, China. Folia Primatologica (in press). 